\title{
Motivational properties of fixed-interval reinforcement: A preliminary investigation
}

\author{
WALTER P. CHRISTIAN and ROBERT W. SCHAEFFER \\ Auburn University, Auburn, Alabama 36836
}

\begin{abstract}
Rats were tested on various fixed-interval (FI) barpress reinforcement schedules with each subject receiving dry food pellets of differing composition. Water was always available in both the test chamber and the home cage. Subjects' water intakes in the experimental chamber increased essentially monotonically as FI values were increased from 2 to $90 \mathrm{sec}$; beyond $120 \mathrm{sec}$, all subjects showed decreased water intakes. Pellet composition affected (1) the rate of development and the maintenance of polydipsia, (2) the number of barpress responses, and (3) the amount of water consumed at each FI value. The possible aversive nature of the absence of sugar in dry-food reinforcement is discussed and interpreted as suggesting a motivational analysis of schedule-induced polydipsia.
\end{abstract}

The discovery that schedule-induced polydipsia can be produced in rats by intermittent food delivery (Falk, 1961) has prompted investigators to test the generality of the phenomenon under a variety of motivational and reinforcement-schedule parameters. Although there is no universally accepted explanation for the phenomenon, recent studies have offered evidence supporting a motivational hypothesis based upon the aversive properties of intermittent food scheduling (Denny \& Ratner, 1970), electric shock (Hymowitz, 1973; King, 1974), and the composition of dry-food reinforcers delivered on lick-contingent fixed-ratio (FR) schedules (Christian, Riester, \& Schaeffer, 1973) and response-independent fixed-time (FT) schedules (Christian \& Schaeffer, 1973).

Studies that have used FI and FT schedules have generally demonstrated an inverted-U relationship between water intake and interpellet interval. Water intake reaches a maximum at intermediate intervals and declines at both smaller and larger intervals (Falk, 1966; Flory, 1971; Segal, Oden, \& Deadwyler, 1965). Previous investigations of the effects of pellet composition upon schedule-induced polydipsia have found an inverse relationship between the sugar content of the pellet and amount of water consumed and number of licks. Both water intake and licking decrease as the sucrose content of the pellet is increased on FT schedules (Christian \& Schaeffer, 1973), and on lick-contingent FR schedules (Christian et al., 1973).

The present experiment was a preliminary study designed to examine the effects of the sugar content of dry-food reinforcement upon the barpress responding and collateral water intakes of rats exposed to FI schedules of various interpellet durations.

Walter P. Christian is presently at Behavior Science Division, CARIH: National Asthma Center, 1999 Julian Street, Denver, Colorado 80204.

\section{METHOD}

\section{Subjects}

Subjects were three female Sprague-Dawley albino rats, about 120 days old at the beginning of the experiment. They had water freely available in the home cage and in the test chamber throughout the entire experiment.

\section{Apparatus}

The experimental space was a standard Grason-Stadler two-bar test chamber, Model E3125AA. The right bar was removed, and its opening covered with a Plexiglas plate mounted flush with the chamber wall. The plate had a circular opening through which the tip of a metal drink tube was accessible. A plastic graduated water reservoir was attached to the right exterior wall of the chamber housing, and plastic tubing connected the reservoir and the metal drink tube. The position of the drink tube was $9.0 \mathrm{~cm}$ above floor level, $8.0 \mathrm{~cm}$ to the right of the manipulandum, $3.0 \mathrm{~cm}$ to the right and $6.0 \mathrm{~cm}$ above the foodcup.

Recording of responses and delivery of Noyes $45-\mathrm{mg}$ food pellets were done automatically by standard relay circuitry. Each lick, barpress, and pellet delivery was recorded on cumulative recorders and on an Esterline-Angus digital operations recorder.

\section{Procedure}

Each subject received a different form of Noyes 45-mg dry-food reinforcer during the experimental sessions. Subject 28 received pellets with $7.5 \%$ sucrose substituted for the Noyes standard $7.5 \%$ glucose content, by weight. Subject 29 received a special formula sugarless pellet. Subject 30 received the Noyes standard-formula pellet.

During the preexperimental phase of the procedure, subjects were given unlimited Purina pelleted Lab Chow in the home cage until free-feeding weights and home-cage water intakes stabilized. Subjects were then reduced to and maintained throughout the remainder of the experiment at $85 \%$ of those free-feeding weights by supplementing food pellets obtained in the test chamber with Purina pelleted Lab Chow given in the home cage approximately $15 \mathrm{~min}$ following each daily test session.

Magazine training was accomplished by placing 10 pellets of the appropriate formula in the foodcup prior to placing each subject in the test chamber. After the subject had consumed the 10-pellet meal, barpress training was begun with each subject receiving pellets of the appropriate formula on a FR 1 reinforcement schedule. Baseline sessions followed, during which 


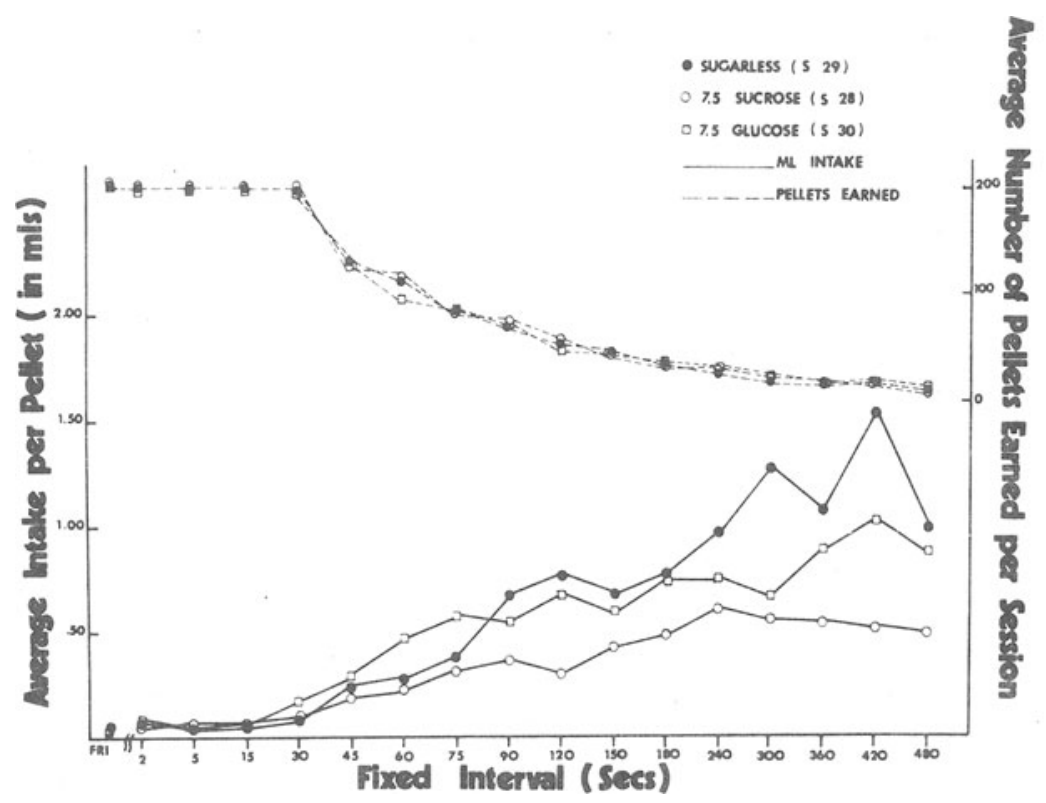

Figure 1. Mean water intake per pellet and pellets earned per session for each subject.

subjects barpressed on a FR 1 schedule for 200 pellets per session. Baseline sessions were continued for 6 days until each subject's water intake in the test chamber had stablized.

During the experimental conditions, subjects were exposed to daily sessions of FI values of $2,5,15,30,45,60,75,90,120$, $150,180,240,300,360,420$, and $480 \mathrm{sec}$ in that order. Subjects were tested for 5 days at each of the four FI values from 2 through $30 \mathrm{sec}$ and remained in the test chamber each session until 200 pellets were received. For FI values 45 through $480 \mathrm{sec}$, subjects were tested for 4 days at each value with session length held constant at $90 \mathrm{~min}$. Differences across sessions with respect to time spent in.the test chamber and number of pellets received per session were taken into account by examining mean water intake per pellet and mean barpresses per pellet for each subject averaged over all sessions at each FI value. Polydipsia was defined as a water intake twice that consumed by each subject during the FR 1 condition, since the FR 1 condition resembles the continuous-feeding baselines employed in previous studies (e.g., Christian \& Schaeffer, 1973).

\section{RESULTS}

The mean FR 1 intakes for Subjects 28, 29, and 30 were $9.00,10,00$, and $8.33 \mathrm{ml}$, respectively. Home-cage intakes are not reported since they were of the same low magnitude as has been consistently reported in previous schedule-induced polydipsia research (cf. Falk, 1961, 1967). Subjects 18 and 30 became polydipsic at FI 30 -sec, and all three subjects were polydipsic from FI 45- through 150 -sec.

As the FI value increased across sessions, subjects differed in terms of (1) the values at which their drinking increased and decreased, and (2) the values at which maximum mean session intakes were obtained. Subject 28 (sucrose) drank the least amount of water across sessions, remaining polydipsic from FI 30 through $150 \mathrm{sec}$. Subject 30 (glucose) remained polydipsic through the 30 - to $240-\mathrm{sec}$ FI range. Subject 29 (sugarless) displayed the greatest range of effective values, remaining polydipsic throughout the 45- to 420 -sec FI values, with the exception of the $360-\mathrm{sec}$ value. All subjects showed a decrease in session water intake at FI values beyond $120 \mathrm{sec}$.

Figure 1 presents intake data for each subject as mean milliliter ingested per pellet. Subject 29 (sugarless) drank more per pellet throughout the 90 - to $480-\mathrm{sec}$ FI range, Subject 30 (glucose) had the next highest intake per pellet, followed by Subject 28 (sucrose). Figures 1 and 2 also indicate that the mean number of pellets earned per session was similar for each subject.

Figure 2 presents the mean number of barpresses per pellet for each subject across sessions. As in the case of milliliters consumed per pellet, barpresses per pellet appeared to be a function of FI value, with barpresses per pellet increasing across sessions for each subject. Subject 28 displayed the greatest number of barpresses per pellet across sessions, followed by Subject 29 and Subject 30 , in that order. However, direct observation of each subject's performance in the test chamber indicated that Subject 29 (sugarless) engaged in considerably more bar-related behavior than either of the sugar-formula subjects. Subject 29 engaged in long periods of constantly depressing the bar via pawing and gnawing so that individual responses during such periods were not recorded.

\section{DISCUSSION}

Subjects became polydipsic at FI $45 \mathrm{sec}$ as compared to their mean intakes on a FR 1 schedule. Intakes for each subject increased to a maximum and then decreased as interpellet interval was increased in length through 14 values from 2 to $480 \mathrm{sec}$. Differences between subjects were obtained in terms of the FI value at which polydipsia was first observed, the value at 


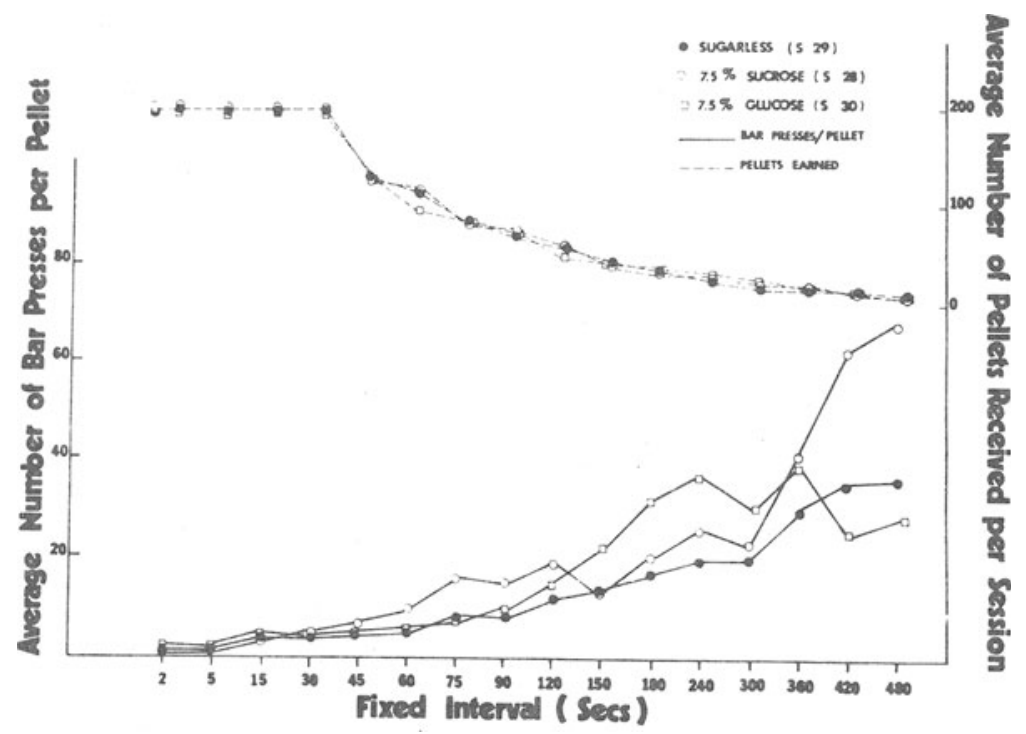

Figure 2. Mean number of barpresses emitted per pellet and pellets earned per session for each subject. which the maximum polydipsia was reached, and the general relationship between FI value and barpresses per pellet as well as millileter intake per pellet across sessions. Pellet composition and interpellet interval were identified as variables affecting the water intake levels and barpress responding of food-deprived rats. These findings support previous studies (Falk, 1966; Flory, 1971; Segal, Oden, \& Deadwyler, 1965) in which polydipsic drinking increased to a maximum level with decreasing pellet-delivery rate. In addition, these results support previous data concerning an effective range of interpellet intervals for producing polydipsia (Flory, 1971) and observations that polydipsia decreases when rats are switched to long (120- to 180 -sec) interpellet intervals (Falk, 1966; Flory, 1971).

These preliminary findings suggest a promising area of research concerning the motivational explanation for the development and maintenance of schedule-induced polydipsia (Christian et al., 1973; Denny \& Ratner, 1970; King, 1974). In addition, these data are interesting in relation to those reported by Brown and Flory (1972) and Richards and Rilling (1972) that increasing the interpellet interval on FI reinforcement schedules increases the aversiveness of the experimental situation and results in increased responding such as attack, aggression, and escape. Specifically, Richards and Rilling (1972) have suggested that the most aversive stimuli of the FI schedule are located during the post reinforcement pause. This finding is supported in the present study, since all subjects spent the postreinforcement period in bursts of licking, followed by bursts of barpress responding toward the end of the interval.

To the extent that increased water intake and increased activity in the experimental chamber (barpressing, nosing \& gnawing) are acceptable indices of aversiveness and increased motivation or "emotional energization" (King, 1974), these data suggest that the absence of sugar in dry-food reinforcement may possess motivational (aversive) properties. Studies currently underway in our laboratory should provide more reliable data concerning the relationship between the motivational and reinforcing effects of pellet sugar content. Despite the encouraging results obtained in the present study, the use of only one subject per pellet formula condition prevents its definitive support for a motivational explanation for schedule-induced polydipsia.

\section{REFERENCES}

Brown, T. G., \& Flory, R. K. Schedule-induced escape from fixed-interval reinforcement. Journal of the Experimental Analysis of Behavior, 1972, 17, 295-403.

Christian, W. P., \& Schaeffer, R. W. Effects of sucrose concentrations" upon schedule-induced polydipsia on a FFI-60-sec. dry-food reinforcement schedule. Psychological Reports, 1973, 32, 1067-1073.

Christian, W. P., Riester, R. W., \& Schaeffer, R. W. Effects of sucrose concentrations upon schedule-induced polydipsia using free and response-contingent dry-food reinforcement schedules. Bulletin of the Psychonomic Society, 1973, 2, 65-68.

Denny, J. R., \& Ratner, S. C. Comparative psychology. Homewood, Illinois: Dorsey, 1970 .

Falk, J. L. Production of polydipsia in normal rats by an intermittent food schedule. Science, 1961, 133, 195-196.

Falk, J. L. Schedule-induced polydipsia as a function of fixed-interval length. Journal of the Experimental Analysis of Behavior, 1966, 9, 37-39.

Flory, R. K. The control of schedule-induced polydipsia: Frequency and magnitude of reinforcement. Learning and Motivation, 1971, 2, 215-227.

Hymowitz, N. Effects of level-press dependent and independent electric shock on schedule-induced water intake. The Psychological Record, 1973, 23, 487-497.

King, G. D. The enhancement of schedule-induced polydipsia by preschedule noncontingent shock. Bulletin of the Psychonomic Society, 1974, 3, 46-48.

Richards, R. W., \& Rilling, M. Aversive aspects of a fixed interval schedule of food reinforcement. Journal of the Experimental Analysis of Behavior, 1971, 17, 405-411.

Segal, E. F., Oden, D. L., \& Deadwyler, S. A. Determinants of polydipsia: IV. Free-reinforcement schedules. Psychonomic Science, 1965, 3, 11-12.

(Received for publication November 14, 1974.) 